\title{
Is There a Metaphysics of Consciousness Without a Phenomenology of Consciousness? Some Thoughts Derived from Husserl's Philosophical Phenomenology
}

\author{
EDUARD MARBACH
}

\begin{abstract}
The paper first addresses Husserl's conception of philosophical phenomenology, metaphysics, and the relation between them, in order to explain why, on Husserl's view, there is no metaphysics of consciousness without a phenomenology of consciousness. In doing so, it recalls some of the methodological tenets of Husserl's phenomenology, pointing out that phenomenology is an eidetic or a priori science which has first of all to do with mere ideal possibilities of consciousness and its correlates; metaphysics of consciousness, on the other hand, has to do with its reality or actuality, requiring an eidetic foundation in order to become scientifically valuable. Presuming that, if consciousness is to be the subject-matter of a metaphysics which is not simply speculative or based on prejudice, it is crucial to get the phenomenology of consciousness right, the paper then engages in a detailed descriptiveeidetic analysis of mental acts of re-presenting something and tries to argue that their structures, involving components of non-actual experiencing, pose a serious problem for a materialistic or physicalistic metaphysics of consciousness. The paper ends with a brief comment on Husserl's broader view of metaphysics, having to do with the irrationality of the transcendental fact, i.e. the constitution of the factual world and the factual life of the mind.
\end{abstract}

Let me first briefly comment on the perhaps somewhat puzzling title of this paper. The philosophical background of my interest in consciousness stems foremost from Edmund Husserl's phenomenology. The term 'phenomenology' (not unlike other terms with the suffix '-logy', e.g. 'bio-logy', 'geo-logy', etc.) in the present context refers to a theoretical enterprise; it is not used to designate phenomenal aspects of experiences, their so-called 'phenomenal', or 'subjective', or 'qualitative' character, or their ways of seeming or feeling for someone, etc., as is often the case in analytical philosophy of mind and consciousness. Husserlian phenomenology can in a first approximation be seen as a reflection-based descriptive science concerned 


\section{Eduard Marbach}

with the essence of the phenomena of consciousness together with the objects of consciousness as such, i.e. as correlates of consciousness. Taken in this sense, the phenomenology of consciousness might appear to be all there is to be philosophically investigated with regard to consciousness and its objects. However, Husserl also had a view on the relationship between phenomenology and metaphysics. ${ }^{1}$ Accordingly, I propose to address the main question, 'Is there a metaphysics of consciousness without a phenomenology of consciousness?' in two sections, followed by a short coda. In the first section, I explain why the short answer, 'no, there isn't', seems to me to be correct by expanding a bit on the question 'why not?' Doing this requires some comment on Husserl's conception of philosophical phenomenology, metaphysics, and the relation between them; obviously, I cannot provide here more than a sketch of this. In section 2, I outline a difficulty I have with materialistic or physicalistic approaches regarding, as it is often put, 'consciousness and its place in nature' or, put another way, with 'the ontological status of consciousness relative to the world of physical reality', a difficulty that arises in my understanding as soon as I take into consideration detailed analyses of certain conscious experiences, particularly cognitive experiences, along a Husserlian approach to the phenomenology of consciousness, as sketched in section 1 . In conclusion, I introduce a twist regarding Husserl's view of metaphysics by very briefly putting forward what he characterized as 'metaphysics in a new sense' which may to some extent at least meet concerns that were at the heart of Timothy Sprigge's metaphysical interests.

\section{The Relationship Between Phenomenology and Metaphysics}

In order to characterize Husserl's view of the relationship between phenomenology and metaphysics, it may be helpful to recall some of the methodological tenets of his phenomenology. Husserl himself, e.g. in his programmatic Inaugural Lecture at the University of Freiburg in 1917, spoke of his enterprise of descriptive 'pure phenomenology' as 'the science of pure consciousness', or as 'science of the pure phenomena', though obviously not taking 'science' in the sense of the empirical natural sciences which rely on objective, third-person data. Rather, he viewed pure phenomenology

1 In this context, I am also reminded of William Seager's Metaphysics of Consciousness (London and New York: Routledge, 1991). 


\section{Is There a Metaphysics of Consciousness?}

as 'a new philosophical basic science'. Husserl's methodology crucially relies on rigorously confining the analysis to that which reflection upon experiences ${ }^{2}$ themselves and purely as such provides - qua consciousness of something of one kind or another, exclusively taken as intentional correlate of the corresponding conscious experience, with a view to elaborating concepts of the very possibility in principle of experiencing this or that in such and such a way. Such properly phenomenological concepts bring forth certain a priori constraints concerning possible explanations of the structures of conscious experiences, and lawful dependencies among them.

In this way, I think, Husserl was able to secure a pure givenness of his research domain as a thematically independent field of investigation. More technically speaking, with the method of what he termed 'phenomenological reduction', he aimed at distinctly delimiting the research domain of phenomenological analysis in its characteristic ownness, that is, at establishing a theme of investigation unmixed with empirical matters of fact. Thus, he left behind the commonsensical everyday conception of conscious experiences as psychological data ascribable to this or that creature, oneself included, understood as this or that empirical self. Moreover, for his philosophical theme of investigation, he also set aside the natural scientific conception of experiences as ultimately neurological processes in the brain. As a consequence of this methodologically motivated restriction, one of the most often recurring expressions in Husserl's writings is that of considering 'consciousness purely as it itself' ('Bewusstsein rein als es selbst'), namely just as it can be given in pure reflection.

To be sure, in the course of the very formation of phenomenological concepts, a given conscious experience of something provides the experiential basis for the sought-after description of its invariant structure or form according to its very possibility (that is, in Husserlian terms, according to its 'eidos' or 'essence'). Thus, for example, a conscious experience of imagining a flying elephant, a case of recollecting an episode from one's own life, an experience of picturing something, etc. will be submitted to such analysis. Of such experiences we all have an everyday knowledge of acquaintance that is reflected in the mental vocabulary of ordinary languages. In a way, then, as Husserl occasionally says, we all 'know' of essential differences of being conscious; however, this knowledge is only

2 In Husserlian phenomenology, the term 'experience', 'Erlebnis'

or 'Bewusstseinserlebnis', covers sensory as well as cognitive, emotional, affective experiences. 


\section{Eduard Marbach}

implicit, and it is just the task of phenomenological reflection and eidetic analysis systematically to explicate distinct phenomenological concepts of the various kinds of consciousness. Based on one's everyday familiarity with a conscious experience of a certain kind as designated in ordinary language, a factually chosen case will be taken $a$ s $a$ purely arbitrary example of its kind, a mere starting point for the analysis. Regarding this methodological step, Husserl liked to refer to the mathematicians' way of starting their analyses by saying, 'there are ...' ('es gibt ...'), say, such and such geometrical figures, prime numbers, etc. ${ }^{3}$ Similarly, Husserl suggested, the phenomenologist adopts the attitude of saying, 'there is, say, an experience of imagining something', of 'picturing something', etc. The chosen experience, forming in this sense nothing more than an arbitrarily selected example, does not bind the phenomenologist qua this or that particular subjective experience, existing as a psychological matter of fact which is such and so determined, occurring for example with this or that degree of vivacity and distinctness of content, etc. The irrelevance of the psychological matter of fact as such for the purpose of the phenomenological concept formation proper can also be seen when we realize that we must engage in a process of varying the conditions in order to define which ones are invariably required, or essential, for making the experience possible as against those that can be changed without altering the essential structure of the experience qua experience of the kind now to be reflectively differentiated from other kinds.

Phenomenological analysis, then, is only interested in truly constituent parts or properties capable of being distinguished in reflection as belonging to, and making together up, a unity of the conscious experience under study in its own essence or nature, i.e. in accordance with the conditions of the possibility of its occurrence, and not of the actuality in its variability as a psychological matter of fact. As Husserl put it in a lecture course of 1907:

The conditions of the 'possibility of experience' are the first. Conditions of the possibility of experience signify, and may signify, here, however, nothing else than all that resides immanently in the essence of experience, in its essentia, and thereby belongs to it irrevocably. The essence of experience, which is

3 See, e.g. E. Husserl, Phenomenology and the Foundations of the Sciences, translated by T. E. Klein, Jr. and W. E. Phol (The Hague: Nijhoff, 1980), §8, 41. See also E. Husserl, Erfahrung und Urteil. Untersuchungen zur Genealogie der Logik, edited by Ludwig Landgrebe (Hamburg: Meiner, 1985), §96. 


\section{Is There a Metaphysics of Consciousness?}

what is investigated in the phenomenological analysis of experience, is the same as the possibility of experience, and everything established about the essence, about the possibility of experience, is eo ipso a condition of the possibility of experience. ${ }^{4}$

Clearly, Husserl understood phenomenology as an eidetic science, or an $a$ priori science of pure consciousness and its correlates, in contrast to the sciences of matters of fact. However, he did not simply limit phenomenological philosophy to the essence or the a priori. Whereas, in his view, eidetic phenomenology has to do with mere ideal possibilities, it is metaphysics which has to do with reality or actuality ('Wirklichkeit'). Husserl characterized 'metaphysics' as 'the genuine ('eigentliche') science of reality' ('Realität') and he made it clear that it was, in the end, also his aim to elaborate a metaphysics, but he would stress that he wanted it to be 'in a serious sense a scientific' metaphysics, as opposed to mere metaphysical speculation, and that therefore he put all his effort first into the 'eidetic foundation' of such a metaphysics. ${ }^{5}$

Husserl had two reasons for the view that pure or transcendental phenomenology qua eidetics had to precede, as its scientific basis, 'metaphysics' considered as the 'absolute science of the factual reality' ('faktische Wirklichkeit'). On the one hand - and I think that this is a truly important point for all studies of consciousness -, consciousness has a very peculiar 'nature' or essence: consciousness, conscious experience, is in an 'incessant flux', in an (as Husserl often put it) 'eternal Heraclitean flux'. As pure consciousness, it is, therefore, scientifically graspable on the basis of essences only. Merely living through individual experiences from moment to moment and reflecting upon them, in this sense having experience ('Erfahrung') of consciousness is not enough for a phenomenological science of consciousness which must provide results that are intersubjectively controllable. To put it succinctly, 'the fact' of this or that occurring conscious experience which serves as the basis for the reflective investigation, is here - in pure reflective phenomenology - 'determinable as that of its essence and only through ('durch') its essence and in no

4 E. Husserl, Thing and Space. Lectures of 1907, translated by Richard Rojcewicz (Dordrecht: Kluwer, 1997), §40, 119.

Compare draft of a letter to Karl Joël, 11. III. 1914 in E. Husserl, Briefwechsel, Band VI. Philosophenbriefe. In Verbindung mit Elisabeth Schuhmann, herausgegeben von Karl Schuhmann (Dordrecht: Kluwer, 1994), $205 f$. 


\section{Eduard Marbach}

way to be documented by means of inductive experience as it is the case in the objective world'. ${ }^{6}$

On the other hand, the reason for the view that phenomenology as eidetics (as science of the possibilities) had to precede 'metaphysics' was for Husserl linked to a general principle of the theory of science, namely that everything factual ('alles Tatsächliche'; all matters of fact, all a posteriori) finds ultimately its full rationality in the eidetic or in the a priori. As Husserl held - very much in line with the traditional so-called rationalists and their 'vérités de raison' as against 'vérités de fait' (Descartes, Leibniz) - all reason (rationality) in the $a$ posteriori has its principles a priori, and these principles are the justifying reasons ('Rechtsgründe') of the objective validity of knowledge. The old ontological doctrine, that knowledge of the possibilities has to precede knowledge of the actualities ('Wirklichkeiten') is, according to Husserl, 'a great truth' if correctly understood and put to use in the right way. ${ }^{7}$

In this sense, then, Husserl considered eidetic phenomenology of the possibilities to be First Philosophy, and metaphysics, as the science of the actualities, is 'Second Philosophy' or 'Empirical Philosophy'. By way of applying pure eidetic phenomenology to matters of fact concerning consciousness - in analogy to applying pure mathematics to the actual world of physics -, empirical research into consciousness would receive its ultimate, i.e. its metaphysical interpretation, behind which it would make no sense to look for a further interpretation. ${ }^{8}$ In short, then, from the point of view of Husserl's philosophical phenomenology there can't be a scientifically valuable metaphysics of consciousness without a phenomenology of consciousness.

6 Compare E. Husserl, The Crisis of European Sciences and Transcendental Phenomenology, translated by David Carr (Evanston: Northwestern University Press, 1970). §52, 178; translation slightly amended.

See, e.g. E. Husserl, Ideen zu einer reinen Phänomenologie und phänomenologischen Philosophie. Erstes Buch. Allgemeine Einführung in die reine Phänomenologie, edited by Karl Schuhmann, Husserliana III/1 (Den Haag: Martinus Nijhoff, 1976), 178; compare also Einleitung in die Logik und Erkenntnistheorie. Vorlesungen 1906/07, edited by U. Melle, Husserliana XXIV (Dordrecht: Martinus Nijhoff, 1984), §40, 236ff.

8 See E. Husserl, Erste Philosophie (1923/24). Kritische Ideengeschichte, edited by Rudolf Boehm, Husserliana VII (Den Haag: Martinus Nijhoff, 1956), 187f., note 1. 


\section{Is There a Metaphysics of Consciousness?}

\section{A Difficulty Regarding Consciousness and Its Place in Nature}

Let us now turn to the above-mentioned difficulty regarding the place of consciousness in the natural world, or put another way, regarding the ontological or metaphysical status of consciousness relative to the world of physical reality. In order to clarify this difficulty, it is necessary to engage in some descriptive-eidetic phenomenology.

Despite all my respect and sympathy for defenders of a unitary view of reality inspired by modern science, I continue to be deeply impressed by results from philosophical phenomenology, providing us with forms or structures of consciousness that in principle seem to have no analogue in the natural world as it is studied by the sciences. ${ }^{9}$ Indeed, as I understand the lesson of the sciences of the external physical world out there and the neurosciences of the brain, the world as it really is in itself exists as a whole of spatial and/or temporal parts-outside-parts, three-dimensional time-slices, all the way down to the ultimate particles on a scale of nanometres, forming cohesions and functional unities involved in all kinds of states that are parts of a system of possible states. By contrast, as Husserl often observed, it belongs to the essence of conscious life not to be structured in terms of 'the spatial outside one another, into one another and through one another and spatial totality' but to contain in itself intentional implications and modifications that cannot be accounted for in spatial terms, even though spatial metaphors in describing forms or structures of conscious experiences crop up time and again. ${ }^{10}$ In Husserl's view, even Brentano was still a naturalist precisely because 'something like intentional implication and intentional analysis as analysis of possibly continuously intertwined sense-giving he did not yet know'. ${ }^{11}$

Clear examples providing evidence for such structures sui generis are given by certain conscious experiences that involve non-actual components or moments in their very way of establishing intentional reference to something when they actually occur. Such a finding, I

9 See E. Husserl, Phänomenologische Psychologie. Vorlesungen Sommersemester 1925, edited by Walter Biemel, Husserliana IX (Den Haag: Martinus Nijhoff, 1962), $35 \mathrm{ff}$.

10 See, e.g. ibid., 37: '... dass es zum Wesen des Bewusstseinslebens gehört, anstelle des räumlichen Aussereinander, Ineinander und Durcheinander und räumlicher Ganzheit ein intentionales ... ineinander meinend Beschlossensein in sich zu bergen...'.

11 Ibid. 


\section{Eduard Marbach}

take it, is very hard to integrate into a description of reality couched in the language of physics or the neurosciences which a complete naturalization of consciousness would have to amount to. The conscious experiences in question make up the large and important class of mentally re-presenting something that is not actually present, 'Akte der Vergegenwärtigung', acts of re-presenting something, which Husserl has investigated extensively. Thus, e.g. when I am engaged in an activity of visually re-presenting, thereby actually intentionally referring to something - say, a past event that I remember visually, or a possible one that I imagine, or an object that I see as being depicted in a picture - then not only is the re-presented object or event consciously given as being not actually present, but at the same time the conscious experience of so referring to something absent contains within its very structure an experiential component of not actually performed perceiving (seeing). If so, then there is something actually occurring in this world an essential property of which is that parts of it are consciously experienced as non-actual.

By the way, I take it that as long as we would confine our attention somewhat abstractly just to sensory conscious experiences occurring here and now in causal interaction with the actual surrounding world, there is not so much reflective work for phenomenology to do regarding structures of these experiences qua structures of consciousness to be articulated in the language of phenomenology. Still, their temporal form, their associative connections and emotional colourings as well as their being part of a horizonal consciousness ('Horizontbewusstsein') could be, and have been, studied phenomenologically as making up their specific what-it-is-likeness qua sensory experiences. Much more structural knowledge would no doubt come from neurophysiological investigation into the specific physical character of the brain states that are causally responsible for the phenomenal character of the corresponding sensory experiences - even though, I think, the so-called 'hard problem' would remain, the problem of explaining why this or that sensory experience should have the specific what-it-is-like aspect it does, rather than having some other phenomenal character or having none at all. ${ }^{12} \mathrm{I}$ am not so thrilled by this problem at the level of sensory experiences given their facticity and hence intractability. It is very tempting to say that I am pleased to have all this motley of sensory impressions, they make life so colorful, but there they are, matters of fact, and,

\footnotetext{
12 Cf. e.g. D. Chalmers, The Conscious Mind (Oxford: Oxford University Press, 1996).
} 


\section{Is There a Metaphysics of Consciousness?}

as Tim Crane disarmingly put it, 'some facts are amazing, and sometimes that's all that can be said'. ${ }^{13}$

Let us stick, then, to kinds of more or less complex non-sensory or properly cognitive acts of re-presenting something, involving also sensory components, to be sure. All such acts, I also take to be in themselves so many modes, simply more complex ones, of what-itis-like to experience them, to live through them and, by having them, to establish intentional reference to something that we experience in its absence. Concerning the conscious experiences themselves, they are exemplified solely in the experiential life of a subject, originally in my own mental life, and this already when they are unreflected on at the time we have them. This, I take it, is just the sense of the present-day phrase that there is 'something-itis-like' to have this or that conscious experience: it pre-reflectively, as Husserl and later on Sartre would have put it, feels somehow or other, say, to perceive something out there, and it feels differently or there is something-other-it-is-like, say, to see something in a picture, or to remember something, etc. Only on the basis of the subject's reflection upon the experiential life can these ways of what-it-is-likeness then be described in general statements regarding their distinct structures, forming thereby descriptive phenomenological concepts of the conscious experiences. To account philosophically for similarities and distinctions among the varieties of the intentionality of conscious experiences and their intentional correlates, as they present themselves as phenomena, i.e. at the level of their phenomenality, was no doubt much at the center of Husserl's eidetic 'science of consciousness'.

Let me expand a little on some distinctions with a more refined analysis along Husserlian lines. The case of picture viewing is particularly well suited to point out what differently structured conscious experiences as such are able to achieve. Consider, for example, a change from a conscious experience of simply perceiving a green pine over there in the meadow to a conscious experience of pictorially re-presenting a green pine and its surroundings. Here, reflective analysis, and I think, at first at least, only reflective analysis, is able to articulate a radical difference regarding the structure of the corresponding conscious experiences themselves and, correlatively, of the ways of givenness of the intentional object, the green pine and its surroundings. To begin with, notice the following aspect. Concretely viewed, i.e. not in isolation, the color green in the pictorial

13 T. Crane, Elements of Mind. An Introduction to the Philosophy of Mind (Oxford: Oxford University Press, 2001), 89. 


\section{Eduard Marbach}

representation is attributed, not to a portion of the flat canvas as such, but rather either to the merely pictorially appearing but not actually given pine on the canvas or to the depicted and again not actually given pine somewhere in the real world or in a fictional space, depending on where the person viewing the picture is focusing her attention. Either way, the presently manifest quality green is here taken, or apprehended, as a property of an object that is not actually present over there where the canvas actually is and where the phenomenal quality green appears. If so - namely in so far as I have conscious experience of the green as of a property of the pine - the phenomenal quality green cannot be given solely in virtue of a sensory-perceptual visual experience; for there is actually no pine to be visually perceived over there on the wall where the painting is hanging. What we have instead is a more complex conscious experience of intentionally referring to the depicted pine by way of seeing as it were the green pine in so far as it appears on a canvas, i.e. as a pictorial object. In its unified structure such an experience also involves as a conscious component among others my seeing the green pine in the mode of non-actuality, namely precisely in so far as the pine seems to appear on the canvas over there that I actually see. In other words, the phenomenal quality green appears no longer as actually belonging to a portion of the canvas or the picture-surface over there. But the pictorially appearing pine's being green - in contradistinction to a perceptually appearing pine's being green - only appears so because of my consciously taking the pictorial object 'pine' to be a representation of an absent (real or imaginary) tree that is only depicted in the picture that I actually see in the present surroundings.

Crucially, the conscious component of my seeing in the mode of nonactuality, as Husserl has convincingly explained, constitutes an intentional modification and can be said to be intentionally implied in the unified conscious experience that I have of seeing something pictorially represented, and clearly this is not a matter of being spatially contained within the experience in the sense of being a part outside other parts. Let me spell this out in a little more detail. What other components are there in such a unified experience of pictorially representing something that do not stand in external spatial relations to one another? Consider first that while I am intentionally referring to the green pine only in so far as it appears in the picture over there, I am simultaneously aware of my present surroundings here and now in virtue of actually perceiving the world around me as well, although somewhat less attentively as long as I am interested in the depicted scene or in the scene as it pictorially appears on the canvas. The fact that I take the pine and its surroundings not to be actually 


\section{Is There a Metaphysics of Consciousness?}

present over there depends, precisely, on a consciously experienced contrast concerning, on the one hand, the ways of givenness of the objects around me, and among them the picture on the wall showing the green pine in its surroundings, and on the other hand, the ways of givenness of the pine either in so far as it pictorially appears on the canvas or is taken as the depicted pine somewhere in the real world or in some fictional world, respectively. There is a clash between that which I take to be actually real around me and that which I take to be just a pictorially represented, not actually given, scene. It is in relation to this pictorially appearing or depicted scene in contrast to the actually perceived surroundings that I speak of seeing something in the mode of non-actuality; for I cannot actually see what is not actually there. To be sure, I actually look over there to the picture and thus, in a sense, I actually see something over there, just as I actually see the wall over there where the whole picture that I actually see is hanging - I actually see patches of green etc. However, as Husserl would urge, as soon as I take those green patches to be ways of appearing of a pine - be it the pine in so far as it appears in the picture or the depicted real or imaginary pine the very experience of seeing is consciously modified: I do not believe I actually see a pine over there. As I understand the matter, my seeing the pine is, however, not simply a particular kind of seeing, a so-called 'representational seeing' or a 'seeing-in' as 'the subsidiary capacity that we also have', besides 'the standard capacity that we have of vision'. ${ }^{14}$ Instead, to the extent that in picture viewing vision is involved in relation to the pictorially appearing objects, it is altogether experientially modified, not unlike what obtains in visually remembering or imagining something that is not actually, presently given, although not quite like it either.

To clarify matters further, notice next that with my seeing as it were the green pine in its surroundings in so far as it appears in the picture or is depicted by the picture that I actually see over there, I do not simply intentionally refer to the pine as if I were seeing the pine itself in some imaginary or remembered place. Yet, there is similarity to some extent between picture viewing and imagining or remembering, namely to the extent, precisely, of involving a visual experience in the mode of non-actuality and an object that is not actually given. For notice that in the case of, say, an experience of simply

14 See, e.g. R. Wollheim, The Mind and Its Depths (Cambridge, Mass.: Harvard University Press, 1993), 188 and C. Peacocke, 'Depiction', The Philosophical Review 96:3 (1987), 383-410, discussing earlier proposals by Wollheim. 


\section{Eduard Marbach}

imagining a pine in imaginary surroundings, the pine would again not actually be given but only appear as it were, this time in relation to an imaginarily occupied point of view of mine from where I would see the tree itself, albeit only as it were, i.e. in a consciously modified manner. This is to say that once again vision would not be functioning in a standard way. My visual experience would indeed not actually be performed but only be re-presented: it would be as if I were seeing the not actually given pine from some place, at some distance and orientation relative to my standpoint in the imaginary space. By contrast, when I intentionally refer to the pine in so far as it appears in the picture, I can do so only because at the very same time I am aware of the pine's merely being a pictorial representation of a tree, be it a real tree in the world or be it merely a fictional tree. The situation, in picture viewing, is indeed rather special, as has often been observed by philosophers and also among scientific psychologists, among whom may be numbered Richard Wollheim, Richard L. Gregory, J. J. Gibson and others. I am neither simply actually perceiving or seeing an object 'in' a picture, nor am I simply purely mentally representing the not actually given object itself, say, in remembering or imagining it in a different space and at a different time. Rather, to sum up, in picture viewing, i.e. when I pictorially re-present some absent object - a thing, person, place, or event - I am intentionally referring to the absent, not actually given object (the so-called sujet, say, of a painting) by means of my representing a non-actual perceiving of the object (the sujet) in so far as it appears in the actually perceived picture while simultaneously presenting my actual surroundings here and now.

In such conscious experiences of purely mentally or of pictorially re-presenting something absent (past, future, merely possible, or elsewhere in space, etc.), as well as in more complex conscious experiences of mentally re-presenting something absent by way of representing an act of pictorially re-presenting it (say, in remembering or imagining an episode of picture viewing), there is always the reflective phenomenological finding of those modified components of nonactuality belonging to the very structure of the actually experienced mental activity: one's being conscious or aware of intending something absent, and one's being innerly conscious or aware of the non-actual experience - in the simplest case, a perceptual experiencethat is implied in the actually occurring establishment of the intentional reference to the absent object. The very givenness of the intended absent, not actually given object as well as the very givenness of the intentionally implied or modified non-actual component of, say, seeing as it were the absent object, is bound to occur within the unified 


\section{Is There a Metaphysics of Consciousness?}

structure of the actually performed conscious experience of re-presenting together with the presentation of the actual surroundings.

In this sense, then, I think that with each instance of an actually occurring conscious experience of re-presenting something absent in virtue of components that are experienced as non-actual, we have clear examples of actually existing entities in our world that do not fit into the framework of the sciences of the natural, physical world. At any rate, those non-actual components of the actually occurring experiences of re-presenting something cannot be understood as being spatially distinct from the actual experiences; being non-actual, they can only be individuated by the experiencing subject as being consciously modified re-presented parts of the subject's actual re-presenting something.

\section{Coda: Metaphysics in a New Sense}

In Section 1, the relationship between phenomenology and metaphysics was presented such that metaphysics would only be at stake in Husserl's overall conception of philosophy as 'second philosophy', or 'empirical philosophy' in the sense of an application of eidetic first philosophy to empirical matters of fact in view of an ultimate interpretation, or a rationalization, of the a posteriori. In conclusion, I would like to point out, albeit very briefly, that Husserl's philosophy of the actuality ('Wirklichkeit'), i.e. his 'metaphysics', was ultimately not simply equivalent to such an eidetic phenomenological interpretation of the sciences of empirical matters of fact. What Husserl, from relatively early on in his work, did consider beyond has to do with 'the irrationality of the transcendental fact which expresses itself in the constitution of the factual world and in the factual life of the mind: thus metaphysics in a new sense' ${ }^{15}$ In Husserl's view, the irrational fact of the rationality of the world was the object of metaphysics in this new sense.

Intriguingly, in his last years, Husserl even questioned his distinction between First and Second Philosophy, formerly oriented after the priority of the eidetically possible over the actual, eidetic philosophy being considered as science of pure possibilities. Even 'the pure I' ('das reine Ich'), belonging to the 'field' of transcendental phenomenology, was for many years conceived by Husserl as a pure possibility, an 'I in general' ('Ich überhaupt'), preceding the actuality. However, in a text from 1931, he totally reversed this conception by noting, with

15 See E. Husserl, Erste Philosophie, op. cit., Chapter 3: 'Rationalismus und Metaphysik der Neuzeit', 188n. 


\section{Eduard Marbach}

regard to the eidos transcendental I, that 'we have here a peculiar and unique case, namely concerning the relationship between fact and eidos': whereas, generally, the being of eidetic possibilities - e.g. in pure mathematics - is free, independent of, the being or not-being of any corresponding realization of such possibilities, 'the eidos transcendental I is inconceivable without a transcendental I as factual'. After speaking of the full ontology as teleology and of the facticity presupposed by this teleology, the text continues: "We end up with ultimate "matters of fact" - Urtatsachen, with ultimate necessities, the Urnotwendigkeiten. But I think them, I question back ... I am the primal fact ('Urfaktum') in this course, I see that these and these primal constituents of my own result in my questioning, as primal structures ('Urstrukturen') of my facticity. And that I in myself carry a core of "primal contingency" ('Kern von "Urzufälligem") in eidetic forms, in forms of potential functioning, in which the mundane eidetic necessities are then founded. I cannot transgress my factual being and in it not the intentionally contained co-being ('Mitsein') of others etc. thus the absolute actuality ('die absolute Wirklichkeit')". ${ }^{16}$

Even though, after this reversal, Husserl did no more systematically elaborate the relationship between the phenomenological eidetics of consciousness, the actuality and the empirical fact, he firmly upheld the eidetics as condition of the possibility of transcendental cognition of consciousness and its objects until as late as in the Crisis of $1936^{17}$. And even though for us the acknowledgment of a thorough facticity of the transcendental I may raise novel and pressing questions regarding the naturalization of consciousness in a phenomenological perspective, it would still seem that the very theme of consciousness as such and of its objects considered as 'correlates' - as it has been the central theme of Husserl's own philosophical phenomenology - remain a valuable theme of philosophical investigation into consciousness, whatever the core of 'primal contingency' in eidetic forms will turn out to be. ${ }^{18}$

University of Bern, Switzerland

16 E. Husserl, Zur Phänomenologie der Intersubjektivität, Dritter Teil 1929-1935, edited by Iso Kern, Husserliana XV (Den Haag: Martinus Nijhoff, 1973), Nr. 22, 385f.

17 E. Husserl, The Crisis, op. cit., see note 6 above.

18 I would like to thank Pauline Phemister for carefully editing and linguistically improving my text; my thanks also go to Pierfrancesco Basile for his help, and to all the organizers for extending the invitation to participate in the Conference in Honour of the late Timothy Sprigge. 